\title{
The need of palliative care education in Brazil
}

\begin{abstract}
Palliative care has highlighted as a rising issue in both developed and developing countries. The increase in the number of patients who need competent and humane assistance has been increasing, and the health teams show lack of preparation in the management of this clientele. The Brazilian Unified Health System presents a public policy for palliative care since 2002 that requires specific training in undergraduate courses to be implemented in a profitable way. Thus, a small review is presented about an extracurricular program developed at a public university in the South of Brazil whose objective is to implement theoretical and practical actions in an active and problematized way to students who wish to improve their knowledge and skills in this area not contemplated in a way in curricula. It is worth noting that actions such as these are notorious and relevant to the training of undergraduates and, however, need to be incorporated into the undergraduate curricula to increase knowledge and guarantee the development of skills and abilities to care for patients and families facing incurable diseases and terminality.
\end{abstract}

Volume 2 Issue 6 - 2018

\author{
Maria Cristina Cescatto Bobroff, Denise \\ Andrade Pereira Meier \\ Departamento de Enfermagem, Centro de Ciências da Saúde, \\ Universidade Estadual de Londrina, Brasil \\ Correspondence: Maria Cristina Cescatto Bobroff, \\ Universidade Estadual de Londrina, Av. Robert Kock n. 60, CEP. \\ 86038-350, Londrina, Paraná, Brazil, Fax 05543337। 2249, \\ Email cristenabobroff@gmail.com
}

Received: August 24, 2018 | Published: November 16, 2018

Keywords: Palliative care, health education, higher education, curriculum.

\section{Abbreviations: PC, palliative care}

\section{Palliative care education in Brazil}

Palliative Care is most effective if it begins earlier in the incurable disease process. So it can lead to a better quality of life, limit hospitalization and the use of health services. ${ }^{1}$ However, most of health professionals all over the world have little or no knowledge about PC principles or its practice. ${ }^{2}$

The Brazilian Ministry of Health published a normative document named National Program of Assistance to Pain and Palliative Care in 2002. This is the first legal framework of PC in the Unified Health System. Based upon national and international epidemiological data about chronic pain as the main cause of human suffering it states pain and $\mathrm{PC}$ as Public Health problems. ${ }^{3}$

Some of the goals of such a program consider the need of consciousness and organization of multidisciplinary health teams regarding the social and economic problems of pain and $\mathrm{PC}$ and provide pain assistance and continuous education of health professionals and community.

Such normative document also states a new culture on pain and palliative care assistance facing the patient in a holistic way involving not only the physical, psychological, social, religious, ethical, and philosophical aspects but including the family, the caregivers and the health team. ${ }^{4}$

The document and other initiatives that followed its publication are still important nowadays and helped to change some of Brazilian suffering chronic pain and PC patients.

There are good health professionals in Brazil and they have made an effort to spread this theme all over the country. They provide multidisciplinary and professional improvement programs and graduate programs in this area in some capitals like São Paulo, among others. Although those are wonderful and respectful initiatives, there is still a gap on PC education in many private and public universities.

Otherwise, another important change - PC scientific knowledge - and how to provide it appropriately must be considered. The World
Health Organization position is that there is poor access to PC and cite some barriers all around the world to overcome this problem such as: the training for health professionals which is often limited or non-existent, the cultural and social barriers, the misconception about PC and about the opioids access and substance abuse, among other related issues.

Most of the Brazilian health undergraduate programs do not offer this content on the school curricula. So, how can a student learn about it or at least have some consciousness about such an important content for his professional life?

Once this knowledge is essential for improvement of an appropriate assistance for population, health professionals must know about the suffering by the disease itself, the other kind of suffering and their reflections. These patient and family cannot face the lack of professional preparation. One that should help them usually does not know how to assist them with the way they need and expect because of misconception and unknowledgement.

The health-teaching model in the majority of schools is the biomedical one. Medical students learn mostly how to cure diseases and nursing students learn less about diseases and more about caring. Unfortunately, none of them learns how to face patients and families' suffering, nor learn about the dying process. In the same way, there is a lack of teaching and learning how to communicate with the suffering and the dying patient.

Most of the health professionals do not know what PC is. Some of them think they know but they know it in a wrong way. Some think $\mathrm{PC}$ is about dying - especially alone - but it is about living with no suffering and having better quality of life in moments of living.

How do health students learn such a content if they are not taught in theory? How to learn it if in practice, many professionals do not know what PC is about and most patients die suffering and maybe alone?

So, there are several questions to be answered, from the perspective of the proper way of offering PC, through studying and teaching inside and outside university walls. 
Fortunately, there are many physicians, nurses, psychologists, physiotherapists and other health professionals studying about PC by themselves and on specialization programs. This is overwhelming because could help changing this awful reality.

\section{What are we doing?}

In a 600 thousand inhabitants city in the South of Brazil there are some isolated PC content in the health undergraduate programs. In everyday practice, students can face an uncontrolled reality where patient isn't assisted in PC for many different reasons. One of them is the lack of knowledge.

In order to help this change in a Public University in Brazil and to provide the dissemination of knowledge about PC to undergraduate and graduate students, we offered an extracurricular activity on this subject in 2018 .

The PC content of the extracurricular program is in modules (PC history, concept and principles, multi-professional team, bioethics, therapeutic communication, pain and other symptoms, types of suffering, death and spirituality). Classes are twice or three times a month using active teaching and learning methodology based on individual or small groups learning activities, seminars, lectures and some ludic activities. There are currently 25 undergraduate students (22 Nursing and 03 Medical School) and 03 graduate health students from the state university and 03 undergraduate students from a private university.

Our specific goal as nursing faculties is to provide qualified scientific knowledge for health area students, so they can disseminate it to their peers, patients, family members and others. Another benefit is to improve the quality of patient care in PC and their families.

While assisting PC patients, they can face death and suffering especially in hospitals and this is inevitable for health professionals. To learn how to deal in practice this should be a discipline in the undergraduate health program curricula. This could benefit patients and families under their care. ${ }^{5}$

We know the offered program and its content is not enough. At least, it is good for this time and for our reality in Brazil where PC has been increasing. There are some suggestions for including PC in the nursing curricula5 and in the medical curricula or as transversal content during the undergraduate program. ${ }^{6}$

The competencies and skills in PC in medical undergraduate education are suggested and the PC is considered as an essential topic according to the prevalence of chronic diseases and the increasing demand for caring of the older people. ${ }^{6}$

A research accomplished in England and Wales estimated future PC need in the population. It was indicated that PC need "will grow in the next 25 years than previously expected" in that region. ${ }^{7}$ The researchers advised that the models of PC must adapt to these changes and suggest "focus on non-specialist health professional education".?

The adaptation on education because of populational aging and reality changing on PC needs maybe will happen all over the world. Health changes happen all the time. Health professionals and educators must improve knowledge to help students face them wherever they are working in the future. The education about this theme has to be required everywhere nowadays and in the future.

\section{What can be done?}

PC is an emerging modality of health care in patients with incurable diseases and in terminality. This theme has expanded worldwide and there are weaknesses in both health services and society to meet this growing demand. It should be stressed that the challenges will only be solved through a professional training that articulates, in an active and problematized way, competences and skills directed to this area. The literature shows isolated and punctual measures developed in undergraduate courses in an attempt to empower future health professionals. However, such actions are insufficient and a curricular reform is necessary for the inclusion of specific subjects on PC in undergraduate courses.

As described above, the extracurricular actions implemented in this program consist of interventions that will sensitize and enable participants; however, in a restricted way and limited to those who have an affinity with the theme. Thus, to ensure the science of all undergraduates, it would be necessary to require participation, not only as a program, but as a compulsory subject. The involvement and improvement, both practical and theoretical, of who are enrolled in the project is notorious, however, the expansion of access and obligatoriness as a discipline would be the best qualification measure of future professionals.

\section{Acknowledgements}

None.

\section{Conflict of interest}

The authors declare no conflict of interest.

\section{References}

1. World Health Organization. Palliative Care. Fact Sheet. 2018.

2. Connor SR, Bermedo MCS. Global Atlas of Palliative Care at the End of Life. 1st ed. England, London: Worldwide Palliative Care Alliance, World Health Organization; 2014:111.

3. Meira JF, Pessimilio KP, Bertelli LO, et al. Legal framework for palliative care the Brazil Unified Health System. Hos Pal Med Int Jnl. 2018;3(3):189-191.

4. Brasil. Portaria do Ministério da Saúde. Brazil: Diário Oficial da República Federativa do Brasil; 2002:16.

5. Ronny A de OC, Arruda AJCG de, Agra G, et al. Reflections about the palliative care in the nursing graduation context. J Nurs UFPE on line Recife. 2016;10(8):3101-3107.

6. Caldas GH de O, Moreira S de NT, Vilas MJ. Palliative care: A proposal for undergraduate education in Medicine. Rev Bras Geriatr Gerontol Rio de Janeiro. 2018;21(3):261-271.

7. Fonseca A, Geovanini F. Palliative care in the formation of health care professionals. Rev bras educ med. 2013;37(1):120-125. 